\title{
Miniaturized dual-band antenna array with double-negative (DNG) metamaterial for wireless applications
}

\author{
Abdulrahman Shueai Mohsen Alqadami \\ Universiti Malaysia Perlis \\ Mohd Faizal Jamlos \\ Universiti Malaysia Perlis \\ Ping Jack Soh \\ Universiti Malaysia Perlis
}

See next page for additional authors

Follow this and additional works at: https://arrow.tudublin.ie/engscheleart2

Part of the Electrical and Computer Engineering Commons

\section{Recommended Citation}

Alqadami, A.S.M., Jamlos, M.F., Soh, P.J. et al. Miniaturized dual-band antenna array with double-negative (DNG) metamaterial for wireless applications. Appl. Phys. A 123, 22 (2017). DOI: 10.1007/

s00339-016-0678-3

This Article is brought to you for free and open access by the School of Electrical and Electronic Engineering at ARROW@TU Dublin. It has been accepted for inclusion in Articles by an authorized administrator of ARROW@TU Dublin. For more information, please contact arrow.admin@tudublin.ie, aisling.coyne@tudublin.ie, gerard.connolly@tudublin.ie.

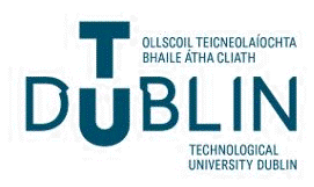




\section{Authors}

Abdulrahman Shueai Mohsen Alqadami, Mohd Faizal Jamlos, Ping Jack Soh, Sharul Kamal Abdul Rahim, Guy Vandenbosch, and Adam Narbudowicz 


\title{
Miniaturized dual-band antenna array with double-negative (DNG) metamaterial for wireless applications
}

\author{
Abdulrahman Shueai Mohsen Alqadami ${ }^{1} \cdot$ Mohd Faizal Jamlos $^{1,2} \cdot$ \\ Ping Jack Soh ${ }^{1}$ - Sharul Kamal Abdul Rahim ${ }^{3}$ - Guy A. E. Vandenbosch ${ }^{4}$. \\ Adam Narbudowicz ${ }^{5,6}$
}

Received: 11 August 2016/Accepted: 9 December 2016/Published online: 19 December 2016

(C) Springer-Verlag Berlin Heidelberg 2016

\begin{abstract}
A miniaturized dual-band antenna array using a negative index metamaterial is presented for WiMAX, LTE, and WLAN applications. This left-handed metamaterial plane is located behind the antenna array, and its unit cell is a combination of split-ring resonator, square electric ring resonator, and rectangular electrical coupled resonator. This enables the achievement of a metamaterial structure exhibiting both negative permittivity and permeability, which results in antenna size miniaturization, efficiency, and gain enhancement. Moreover, the proposed metamaterial antenna has realized dual-band operating frequencies compared to a single frequency for normal antenna. The measured reflection coefficient $\left(\mathrm{S}_{11}\right)$ shows a $50.25 \%$ bandwidth in the lower band (from 2.119 to $3.058 \mathrm{GHz}$ ) and $4.27 \%$ in the upper band (from 5.058 to $5.276 \mathrm{GHz}$ ). Radiation efficiency obtained in the lower and upper band are $>95$ and $80 \%$, respectively.
\end{abstract}

Mohd Faizal Jamlos

mohdfaizaljamlos@gmail.com

1 Advanced Communication Engineering Centre (ACE), School of Computer and Communication Engineering, Universiti Malaysia Perlis (UniMAP), 01000 Kangar, Perlis, Malaysia

2 Faculty of Mechanical Engineering, Universiti Malaysia Pahang (UMP), 26600 Pekan, Malaysia

3 Wireless Communication Centre (WCC), Universiti Teknologi Malaysia (UTM), 81310 Skudai, Johor, Malaysia

4 ESAT-TELEMIC Research Division, KU Leuven, Kasteelpark Arenberg 10, Box 2444, 3001 Louvain, Belgium

5 Institute of High Frequency Technology, RWTH Aachen University, Melatener Str. 25, 52074 Aachen, Germany

6 Dublin Institute of Technology, Kevin Street, Dublin 8, Ireland

\section{Introduction}

In the last few years, there has been a significant interest in using metamaterial structures to realize the new electromagnetic properties that may not be readily obtainable in nature $[1,2]$. An example of this is metamaterial structures that produces a negative refractive index (NRI) with negative permittivity and permeability properties that are known as double-negative metamaterial (DNM) [3]. They are widely investigated due to their potential applications in various fields such as wireless technology and microwaves. These novel engineered materials are first introduced by Veselago [4] and verified experimentally after several decades [5].

Metamaterial promises a new class of antennas due to their effectiveness in improving antennas' performance and size miniaturization [6-8]. Meanwhile, patch antennas are chosen in this work as they feature advantageous physical and electromagnetic properties such as low profile, low cost, small size, reasonable gain, and good radiation patterns [9]. However, conventional patch antennas suffer from narrow bandwidths, low gains and efficiencies, and large sizes at low frequencies. Therefore, numerous types of metamaterials structures such as SRR, SERR, capacitance-loaded strip (CLS), spiral resonators (SR) and periodic array structures are proposed to enable improvement of their physical and electrical features [10-12]. To date, different metamaterial structures have been investigated for antenna miniaturization, improving gain and efficiency and enabling multi-band operation [13]. For instance, SRRs unit cells structures are generally employed as loading structure placed along an antenna to reduce the resonant frequency of an antenna [10, 14, 15].

This paper presents a miniaturized dual-band antenna array using a novel combination of DNG metamaterial unit 
cell for WiMAX, LTE, and WLAN applications. The proposed left-handed metamaterial unit cell located on the reverse of the antenna substrate combines the SRR, SERR, and rectangular ELC resonator. This structure exhibits negative refractive index (NRI) and negative permittivity and permeability, which results in a compact, dual-band antenna array $(0.17 \lambda \times 0.36 \lambda \times 0.004 \lambda)$ with more than $95 \%$ of radiation efficiency.

\section{Antenna design geometry}

Figure 1a shows the front view of the combined unit cell structure. It combines the SRR and SERR which are both magnetic resonant structures. The perpendicular magnetic field produced by those cells generates negative permeability. Meanwhile, the rectangular ELC resonator is located between the above mentioned cells and is used to generate negative permittivity. The dimensions of the proposed unit cells are illustrated in Table 1. Figure 1b-e illustrates the real and imaginary values of impedance, refractive index, permeability, and permittivity. The result indicated that the proposed structure features a negative refractive index from 1.5 to $3.6 \mathrm{GHz}$.

Figure 2a, b illustrates the simulated geometry of the proposed antenna. It is an array containing 10 elements; each rectangular element is dimensioned at $4 \times 4 \mathrm{~mm}^{2}$. The antenna is fed using a combination of both series and corporate feed techniques. It is designed on a $0.51-\mathrm{mm}-$ thick RT/duroid ${ }^{\circledR} 5880$ substrate. The metamaterial unit cells and ground plane are located on the rear side of the antenna. The dimensions of the proposed antenna array are listed in Table 1.

\section{Experimental results and discussion}

Figure 3 shows the fabricated 10-element array prototype. Its reflection coefficients $\left(\mathrm{S}_{11}\right)$ are then measured in an anechoic chamber using an Agilent E8051C network analyzer and compared with simulations in Fig. 4. It covers two bands which fulfill the WLAN, LTE, and WiMAX

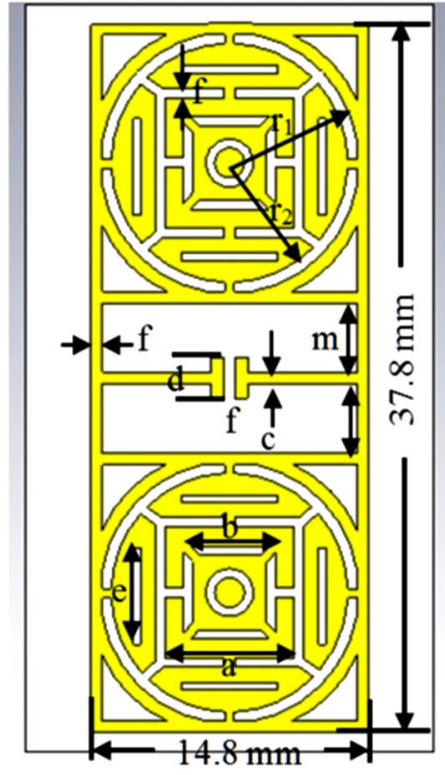

(a)

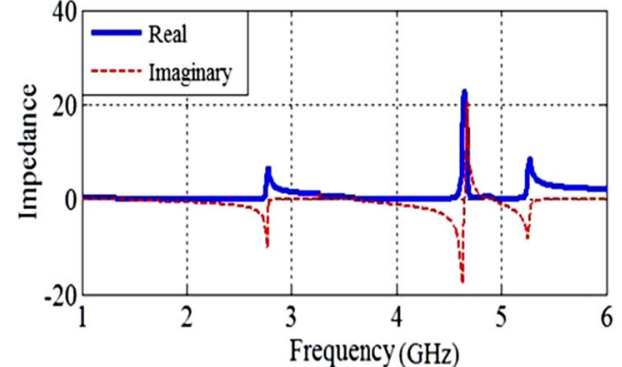

(b)

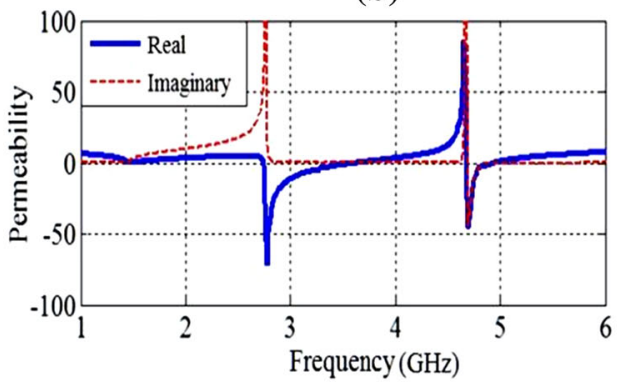

(d)

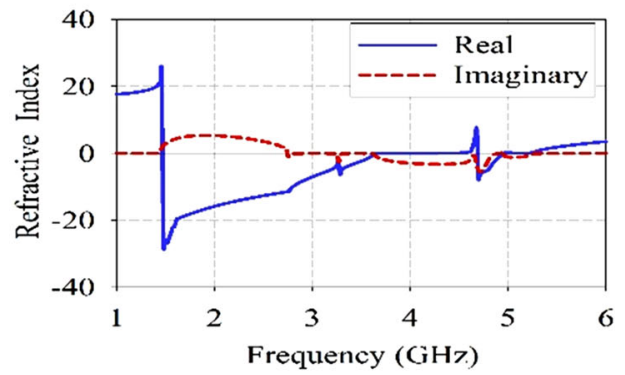

(c)

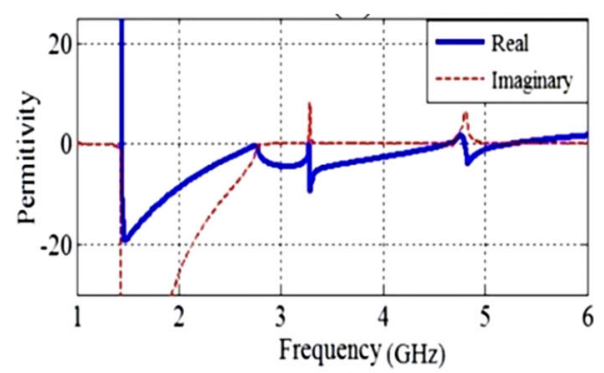

(e)

Fig. 1 Metamaterial unit cells and simulated results, a unit cell structure, $r 1=7 \mathrm{~mm}$ and $r 2=6.4 \mathrm{~mm}$, b impedance, c refractive index, d permeability, e permittivity

Table 1 Parameter dimensions of the proposed antenna

\begin{tabular}{llllllllllllll}
\hline Para. & $\begin{array}{l}\text { Value } \\
(\mathrm{mm})\end{array}$ & Para. & $\begin{array}{l}\text { Value } \\
(\mathrm{mm})\end{array}$ & Para. & $\begin{array}{l}\text { Value } \\
(\mathrm{mm})\end{array}$ & Para. & $\begin{array}{l}\text { Value } \\
(\mathrm{mm})\end{array}$ & Para. $\begin{array}{l}\text { Value } \\
(\mathrm{mm})\end{array}$ & $\begin{array}{c}\text { Para. } \\
\text { Value } \\
(\mathrm{mm})\end{array}$ & $\begin{array}{c}\text { Para. } \\
(\mathrm{mm})\end{array}$ \\
\hline $\mathrm{a}$ & 7 & $\mathrm{~d}$ & 2.2 & $\mathrm{w}_{\mathrm{p}}$ & 4 & $\mathrm{w}_{2}$ & 0.5 & $\mathrm{w}_{5}$ & 0.6 & $1_{2}$ & 1.5 & $1_{5}$ & 2 \\
$\mathrm{~b}$ & 4.2 & $\mathrm{e}$ & 5.2 & $\mathrm{l}_{\mathrm{p}}$ & 4.4 & $\mathrm{w}_{3}$ & 0.7 & $\mathrm{w}_{6}$ & 0.6 & $1_{3}$ & 2 & $1_{6}$ & 5 \\
$\mathrm{c}, \mathrm{f}$ & 0.6 & $\mathrm{~m}$ & 3.7 & $\mathrm{w}_{1}$ & 1 & $\mathrm{w}_{4}$ & 1 & $\mathrm{l}_{1}$ & 10.4 & $1_{4}$ & 4.8 & $1_{7}$ & 1 \\
\hline
\end{tabular}




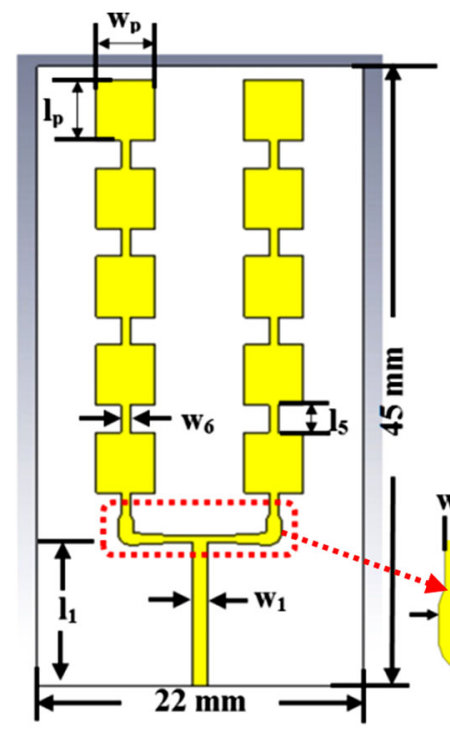

(a)

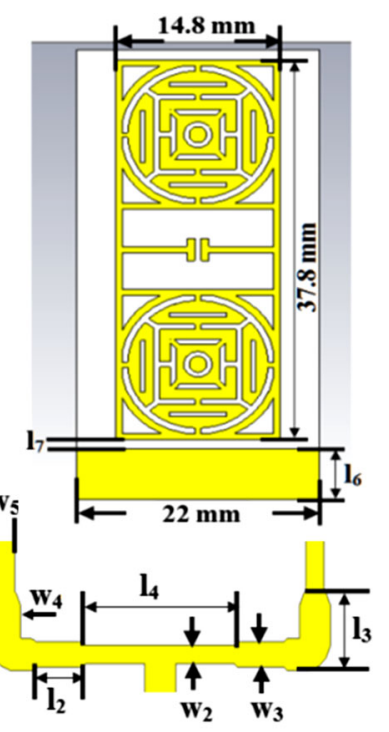

(b)
Fig. 2 Geometry of the proposed antenna and reflection coefficient $\left(\mathrm{S}_{11}\right)$, a front view, b back view

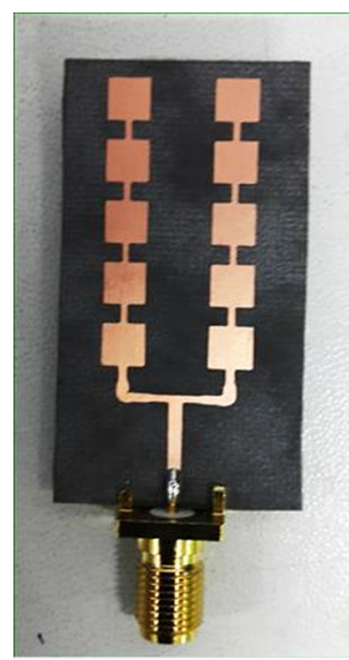

(a)

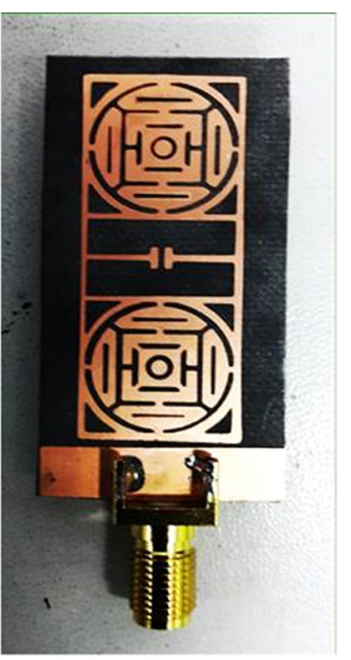

(b)
Fig. 3 Fabricated prototype of the proposed antenna array, a front view, $\mathbf{b}$ back view (unit cell and ground plane)

operating bands. The simulated and measured reflection coefficient $\mathrm{S}_{11}$ is below $-10 \mathrm{~dB}$ for both operating bands. The measured results indicated an increase in the bandwidth for the first band from $40.08 \%$ (simulated) to $50.25 \%$ (measured) and the second band bandwidth slightly increased to $4.27 \%$. This is due to the fabrication accuracy issues of the small unit cells.

Figure 5 illustrates the gain, radiation, and total efficiencies of the proposed antenna. It can be seen that the maximum gain of the proposed antenna in the first band is $2.8 \mathrm{~dB}$ and is increased to $3.48 \mathrm{~dB}$ in the second band.

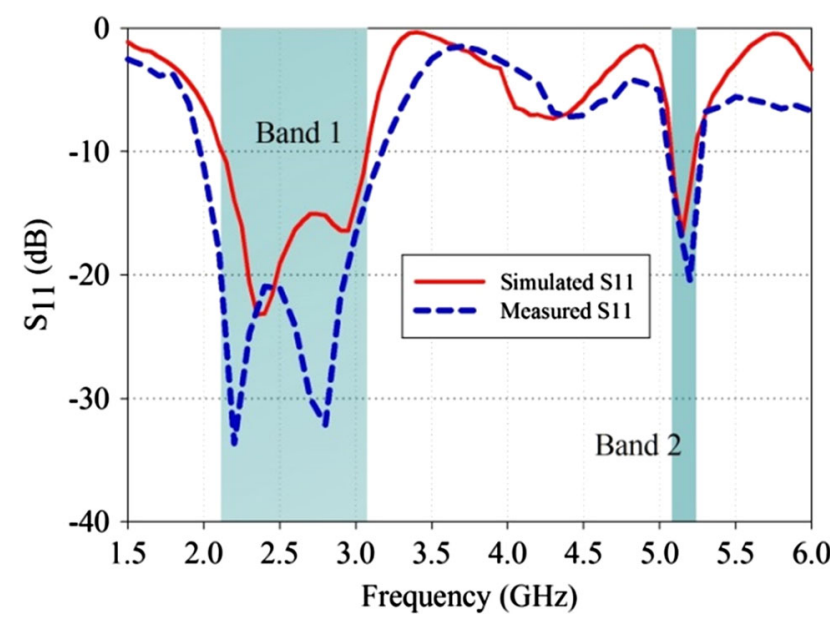

Fig. 4 Simulated and measured reflection coefficient $\left(S_{11}\right)$

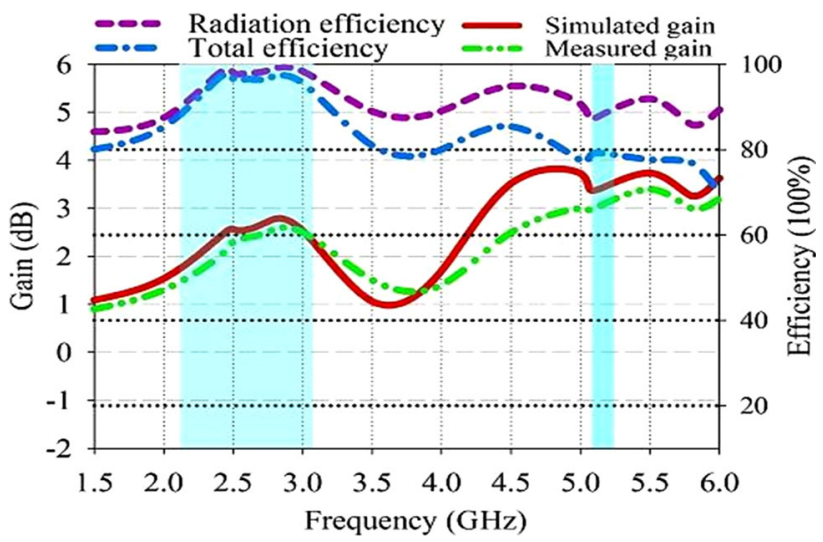

Fig. 5 Gain and efficiency of the proposed antenna

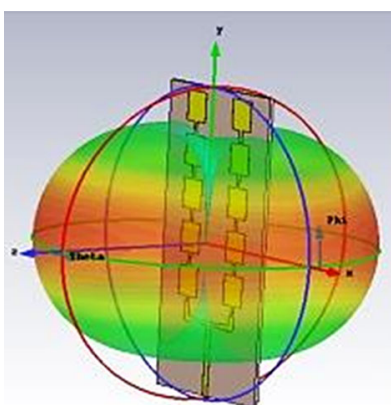

(a)

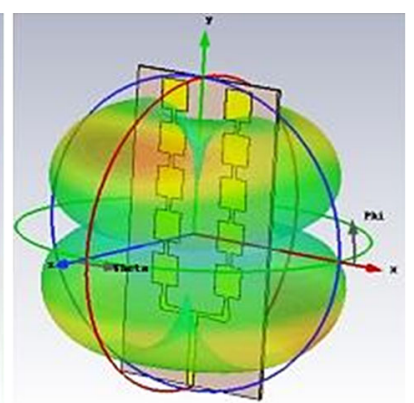

(b)
Fig. $63 \mathrm{D}$ radiation pattern of the proposed antenna at: a $2.4 \mathrm{GHz}$, and b $5.1 \mathrm{GHz}$

Conversely, the radiation and total efficiencies in the first band varies between 88 and $98.5 \%$ while for the second band these parameters have been reduced to 88 and $79 \%$, correspondingly. Radiation patterns shown in Figs. 6 and 7 


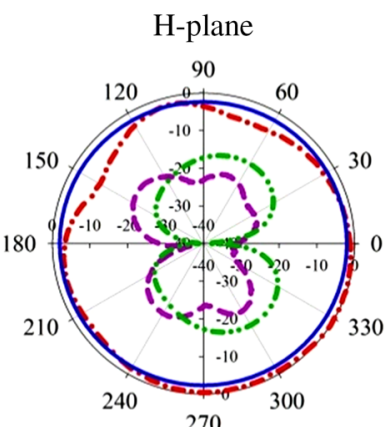

(a)

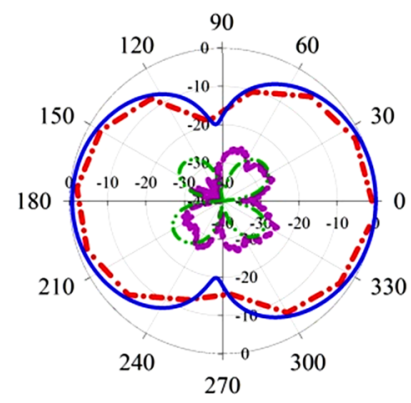

(c)

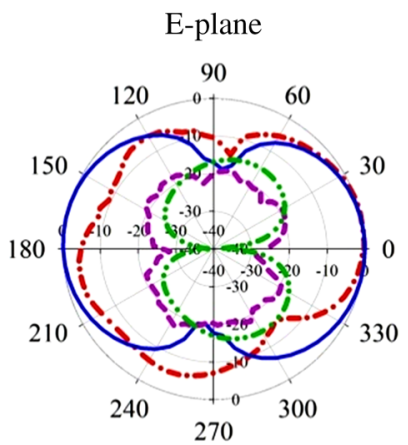

(b)

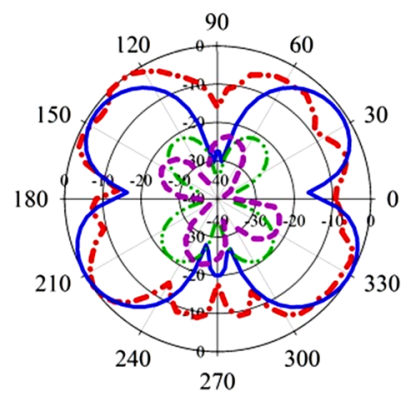

(d)

\section{- Co-polar (simulated) -... X-polar (simulated)} -. Co-polar (measured) _.. X-polar (measured)

Fig. 7 Simulated and measured radiation patterns of the proposed antenna at: a $2.4 \mathrm{GHz}$ (H-plane), b $2.4 \mathrm{GHz}$ (E-plane), c $5.1 \mathrm{GHz}(\mathrm{H}-$ plane), d $5.1 \mathrm{GHz}$ (E-plane)

Table 2 Performance of different metamaterial-based antennas

\begin{tabular}{llcll}
\hline References & $\begin{array}{l}\text { Operating } \\
\text { freq. }(\mathrm{GHz})\end{array}$ & $\begin{array}{l}\text { Size } \\
W \times L\left(\mathrm{~mm}^{2}\right)\end{array}$ & $\begin{array}{l}\text { Max. } \\
\text { efficiency } \\
(\%)\end{array}$ & Gain $(\mathrm{dB})$ \\
\hline$[1]$ & $2-6.3$ & $38 \times 32$ & - & $1-8$ \\
{$[7]$} & $1.2 / 1.59$ & $86.4 \times 86.4$ & - & $3.3-4.2$ \\
{$[10]$} & 0.305 & $21 \times 21$ & 17.5 & - \\
{$[19]$} & 0.40 & $350 \times 350$ & - & $0.5-4.3$ \\
This work & $2.11-3.05 / 5.2$ & $22 \times 45$ & 98.5 & $2.8-3.48$ \\
\hline
\end{tabular}

indicate an omnidirectional behavior in the first band (at $2.4 \mathrm{GHz}$ ) while a bi-directional in the second band (at $5.1 \mathrm{GHz}$ ). Furthermore, the degradation in total efficiency in the second band is due to the fact the small antenna showed high losses at higher frequency and thus reducing its total efficiency [16-18].

An overview of such antennas published in literature is given in Table 2. It can be observed that the antenna proposed in this work results in a significant size miniaturization while maintaining high efficiency in comparison to the state of the art.

\section{Conclusions}

A miniaturized dual-band antenna array using DNG metamaterials is presented. A novel combination of lefthanded metamaterial SRR, SERR, rectangular electrical coupled (ELC) resonator unit cells is proposed. The features of negative permittivity, permeability and refractive index (NRI) are validated numerically from the proposed unit cells structure. They are then placed on the reverse side of an antenna array. The measured reflection coefficient $\left(S_{11}\right)$ shows a $50.25 \%$ of bandwidth in the first band (from 2.119 to $3.058 \mathrm{GHz}$ ) and $4.27 \%$ (from 5.058 to $5.276 \mathrm{GHz}$ ) in the second band. Radiation efficiencies obtained from this structure are $>95 \%$ (in the first band) and $80 \%$ in the second band.

\section{References}

1. M.A. Wan Nordin, M.T. Islam, N. Misran, A compact wideband coplanar waveguide fed metamaterial-inspired patch antenna for wireless application. Appl. Phys. A 109(4), 961-965 (2012)

2. A. Sarkhel, D. Mitra, S.R.B. Chaudhuri, A compact metamaterial with multi-band negative-index characteristics. Appl. Phys. A 122(4), 1-10 (2016)

3. S.A. Pope, Double negative elastic metamaterial design through electrical-mechanical circuit analogies. IEEE Trans. Ultrason. Ferroelectr. Freq. Control 60(7), 1467-1474 (2013)

4. V.G. Veselago, The electrodynamics of substances with simultaneously negative values of $\varepsilon$ and $\mu$. Sov. Phys. Usp. 10, 509-514 (1968)

5. D.R. Smith, W.J. Padilla, D.C. Vier, S.C. Nemat-Nasser, S. Schultz, Phys. Rev. Lett. 84, 4184 (2000)

6. J.C. Myers, P. Chahal, E. Rothwell, L. Kempel, A multilayered metamaterial-inspired miniaturized dynamically tunable antenna. IEEE Trans. Antennas Propag. 63(4), 1546-1553 (2015)

7. S.N. Burokur, A.C. Lepage, S. Varault, X. Begaud, G.P. Piau, A. de Lustrac, Low-profile metamaterial-based L-band antennas. Appl. Phys. A 122(4), 1-7 (2016)

8. P. Jin, R.W. Ziolkowski, Broadband, efficient, electrically small metamaterial-inspired antennas facilitated by active near-field resonant parasitic elements. IEEE Trans. Antennas Propag. 58(2), 318-327 (2010)

9. C.A. Balanis, Antenna Theory: Analysis And Design (Wiley, Hoboken, 2005)

10. O.S. Kim, O. Breinbjerg, Miniaturised self-resonant split-ring resonator antenna. Electron. Lett. 45(4), 196-197 (2009)

11. Yuandan Dong, Tatsuo Itoh, Metamaterial-based antennas. Proc. IEEE 100(7), 2271-2285 (2012)

12. M.M. Islam, M.T. Islam, M. Samsuzzaman, M.R.I. Faruque, N. Misran, M.F. Mansor, A miniaturized antenna with negative index metamaterial based on modified SRR and CLS unit cell for UWB microwave imaging applications. Materials 8(2), 392-407 (2015)

13. K. Li, C. Zhu, L. Li, Y.M. Cai, C.H. Liang, Design of electrically small metamaterial antenna with ELC and EBG loading. IEEE Antennas Wirel. Propag. Lett. 12, 678 (2013)

14. J.P. Chen, P. Hsu, A compact strip dipole coupled split-ring resonator antenna for RFID tags. IEEE Trans. Antennas Propag. 61(11), 5372-5376 (2013) 
15. X.H. Song, L.L. Chen, C.H. Wu, Y.N. Yuan, Study on an SRR-shaped left-handed material patch antenna. J. Opt. 13(3), 35402 (2011)

16. D.R. Jackson, N.G. Alexopoulos, Communications: simple approximate formulas for input resistance, bandwidth, and efficiency of a resonant rectangular patch. IEEE Trans. Antennas Propag. 39(3), 407-410 (1991)

17. G.S. Smith, Efficiency of electrically small antennas combined with matching networks. IEEE Trans. Antennas Propag. 25(3), 369-373 (1977)
18. A. Galehdar, D.V. Thiel, S.G. O'Keefe, Antenna efficiency calculations for electrically small, RFID antennas. IEEE Antennas Wirel. Propag. Lett. 6, 156-159 (2007)

19. A. Presse, A.C. Tarot, Miniaturized bendable $400 \mathrm{MHz}$ artificial magnetic conductor. Appl. Phys. A 122(4), 1-5 (2016) 